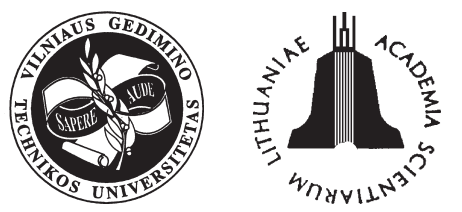

ISSN 1648-4142 TRANSPORT

http:/www.vtu.lt/english/editions

TRANSPORT - 2005, Vol XX, No 3, 96-98

\title{
THE INFLUENCE OF EFFECTIVE UTILIZATION DEGREE OF DIESEL ENGINE CYLINDER AIR CHARGE ON SOOT EMISSION AND INDICATED EFFICIENCY
}

\author{
Dmitry Matievsky, Andrew Svistula \\ Altai State Technical University, 46, Lenin St., 656038 Barnaul, Russia. \\ Tellfax: (+3852260516), Tel: (+3852367621), e-mail: sle@agtu.secna.ru, sae59@mail.ru \\ Received 2005-01-06; accepted 2005-03-25
}

\begin{abstract}
Mathematical simulator results of the influence of effective utilization degree of (a diesel engine) cylinder air charge on soot emission and connected losses of heat are given in this paper. Increase reserve of the indicated efficiency by the reduction of inopportunity of soot burning and radiation heat exchange loss is shown.
\end{abstract}

Keywords: diesel engine, soot emission, air charge, heat, losses of heat, combustion, indicated efficiency.

\section{Introduction}

The extremely non-homogeneous structure of a mix is formed in the cylinder of a diesel engine as a result of jet mix formation and diffusive combustion of a non-homogeneous mix is always accompanied by intensive soot emission. The principal cause of this phenomenon consists in real existence of local physical conditions for the course of reactions of high-temperature pyrolysis of fuel hydrocarbons. The soot not burned down in the cylinder of a diesel engine represents mechanical non-burning fuel and enters as a component into the concept of heat combustion. The great bulk of soot burns out on a line of expansion untimely when allocated heat is used ineffectively with low efficiency. Simultaneously, losses of energy (as radiant heat) considerably grow as a result of high radiating ability of soot. Besides, some share of the heat allocated at the combustion of soot is removed by convection. Thus, the participation of soot in a running cycle influences the indicated efficiency through incompleteness and inopportuneness of combustion, radiating and convection heat exchange as it is shown in the article [1].

\section{Research technique}

The change of the structure of a fuel-air mix in a burning zone $\alpha_{c}=\psi(\varphi)$, the characteristic of thermal emission $x=f(\varphi)$ should be known for carrying out the mathematical prognosis of the influence of changeability of the structure of a fuel-air mix in a burning zone at soot emission, the parameters of a running cycle and display efficiency of a diesel engine cycle.

N. Razlejtsev's techniques of the account of a fuel-air mix structure in a burning zone is of the greatest interest. It is finished with the numerical decision distinguished by simplicity and allows to take into account the dependence of combustion coefficient $x(\varphi)$ and factor $\alpha_{c}(\varphi)$ or the named concept of effective utilization degree of air charge $\xi_{b}$ [2].

$$
\alpha_{c}(\varphi)=\alpha \xi_{b} / x
$$

The coefficient $\xi_{b}=f\left(\bar{\varphi}_{z}\right)$ unequivocally establishes the connection between the value of air surplus coefficient in a burning zone $\alpha_{c}(\varphi)$ and the characteristic of burning out of fuel $x(\varphi)$, also it reflects a degree of effective utilization of the cylinder air charge.

We shall take advantage of a technique [1, 3] for the estimation of soot influence at the formation of indicated efficiency $\eta_{i}$. We shall estimate the complex influence of soot in $\eta_{i}$ through the change of all coefficients of non-use of heat in a cycle according to the equation:

$$
\delta_{i}^{c}=x^{c}-\left(\delta_{s}{ }^{c}+\delta_{u t}{ }^{c}+\delta_{k}{ }^{c}+\delta_{w r}{ }^{c}+\delta_{w c}{ }^{c}+\Delta_{u c}{ }^{c}\right),
$$

where $\delta_{i}^{c}$ is a coefficient of the heat allocated as a result of burning out of soot; $x^{c}$ is a share of the heat 
allocated in a cycle at burning out of soot, coefficients of non-use of heat are: $\delta_{s}^{c}-$ standard cycle, $\delta_{u t}{ }^{c}-$ owing to the inopportuneness of heat emission, $\delta_{k}^{c}-$ owing to the change of thermal capacity of the working medium, $\delta_{w r}{ }^{c}$ - owing to the radiating heat exchange by radiation of burning soot, $\delta_{w c}{ }^{c}$ - owing to convection heat exchange, $\Delta_{u c}{ }^{c}-$ owing to the incompleteness of soot combustion.

The soot has the greatest value in negative influence at indicated efficiency through the inopportuneness of combustion $\delta_{u t}^{c}$. Then we shall be limited to prognosticate the influence of soot at cycle profitability by the change of the inopportuneness of soot combustion $\delta_{u t}{ }^{c}$, incompleteness $\Delta_{u c}{ }^{c}$ and radiating heat exchange $\delta_{w r}{ }^{c}$. It will decrease the quantitative estimation of soot influence an the indicated efficiency of a running cycle.

For the calculation of $\Delta_{u c}{ }^{c}$ it is enough to know the dependence of the heat allocation coefficient from the heat of soot combustion $x^{c}$.

The utilization efficiency of soot combustion heat can be found by the equation

$$
\eta_{i}^{c}=\delta_{i}^{c} / x^{c}
$$

3. The results of prognoses of the soot quantity in the cylinder of a diesel engine and the efficiency of its burning out

Researches were carried out into a mathematical model of the process of soot emission [a]. The model of calculation of the running cycle added technique of the analysis of the indicated efficiency in view of soot emission influence at $\eta_{i}[1]$.

We shall consider the characteristic of heat emission as the sum of two components

$$
x=x^{u c}+x^{c} .
$$

The part $x^{c}$ characterizes the heat of soot burning out and the part $x^{u c}=x-x^{c}$ - all other heat.

The character of a curve course $\xi_{b}(\varphi)$ is determined by the coordinates of its minimum $\bar{\varphi}_{z o}=0,33$ and $\xi_{b o}=0,2-0,8$.

The dependence of the soot concentration in the cylinder from the air charge utilization efficiency is shown in Fig 1. It is visible that the more homogeneous mix is formed during burning, the curve $x=f(\varphi)$ is more abruptly placed, the concentration of soot in the cylinder is less, the speed of a soot combustion process starts to outstrip the speed of a soot formation process earlier. When $\xi_{b}=1$ (it is possible only theoretically), the soot concentration in the cylinder is minimum. The quantity of soot

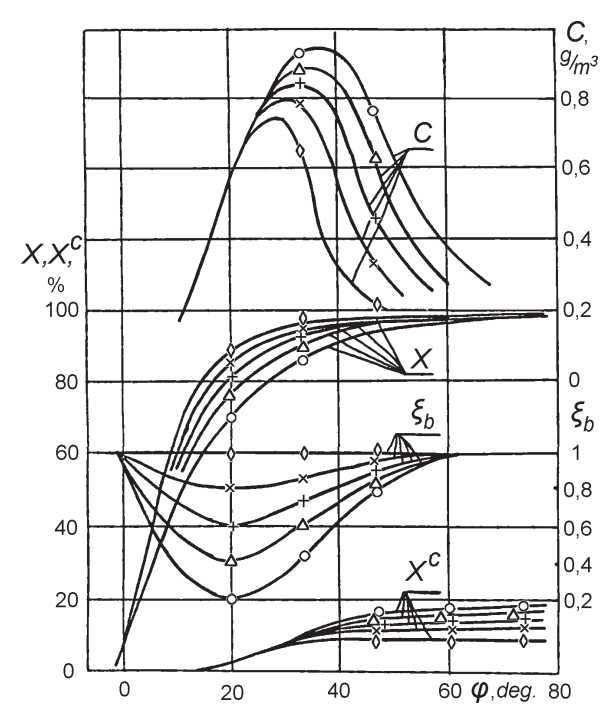

Fig 1. The influence of function $\xi_{b}(\varphi)$ in characteristics of fuel combustion and soot concentration - $-\xi_{b o}=1,0 ; \times-\xi_{b o}=0,8 ;+-\xi_{b o}=0,6 ; \Delta-\xi_{b o}=0,4 ;>\bullet-\xi_{b o}=$ 0,2

combustion heat is $x^{c}=9-19 \%$ in the heat brought with fuel, when $\xi_{b o}=0,2-1$ accordingly and the greater value of $x^{c}$ corresponds the smaller value of $\xi_{b}$.

It is of certain interest in the communication of soot emission character in the cylinder and the indicated efficiency of a cycle. As it was noted above and in [1] the great bulk of soot burns down during an expansion process and it has the great radiating ability, i.e. it has significant losses of heat owing to the inopportuneness of combustion and radiating heat exchange. Fig 2 shows the change of indicated

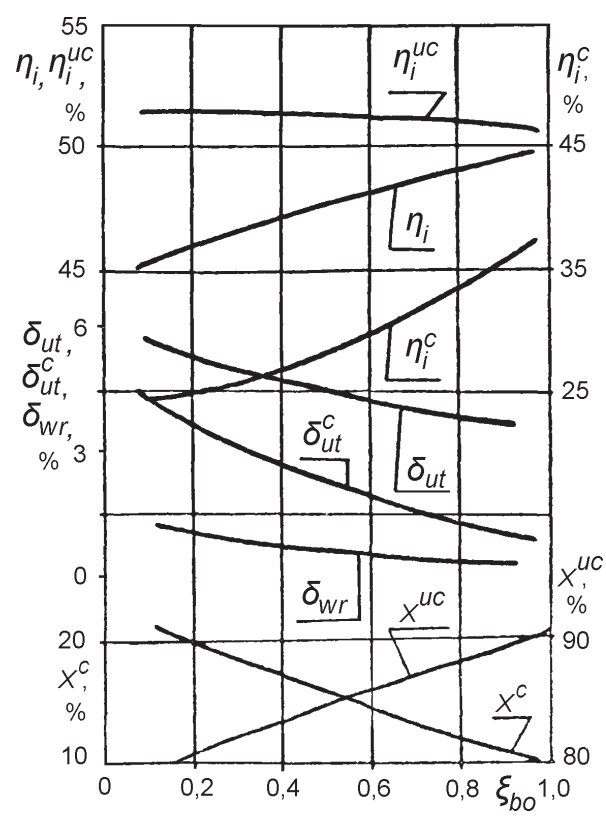

Fig 2. The dependence of parameters of thermal emission, heat utilization efficiency in a cycle, indicated efficiency from the air charge utilization efficiency in the cylinder 
Results of full allocation of heat losses

\begin{tabular}{|l|l|l|l|l|l|l|l|l|l|l|}
\hline & $x^{c}, \%$ & $\delta_{s}^{c}, \%$ & $\delta_{u t}{ }^{c}, \%$ & $\delta_{k}^{c}, \%$ & $\delta_{w r}^{c}, \%$ & $\delta_{w c}^{c}, \%$ & $\Delta_{u c}{ }^{c}, \%$ & $\Sigma \delta^{c}, \%$ & $\delta_{i}^{c}, \%$ & $\eta_{i}^{c}$ \\
\hline$\xi_{b o}=0,4$ & 17,3 & 5,6 & 2,6 & 2,3 & 0,8 & 0,8 & 0,6 & 12,7 & 4,6 & 0,27 \\
\hline$\xi_{b o}=1$ & 9,4 & 3,0 & 0,7 & 1,24 & 0,2 & 0,4 & 0,3 & 5,84 & 3,56 & 0,38 \\
\hline
\end{tabular}

efficiency $\eta_{i}$, noted components of non-use of heat $\delta_{u t}^{c}, \delta_{u t}, \delta_{w r}{ }^{c}$, utilization efficiency of soot combustion heat $x^{c}$ and other heat $x^{u c}$, which is counted up by the equations:

$$
\eta_{i}^{c}=\delta_{i}^{c} / x^{c} ; \quad \eta_{i}^{u c}=\delta_{i}^{u c} / x^{u c} .
$$

It is seen in Fig 2 that indicated efficiency $\eta_{i}$ decreases and non-use of heat owing to the inopportuneness $\delta_{u t}$ considerably increases when soot combustion heat $x^{c}$ increases (value of $\xi_{b o}$ decreases) and the change of $\delta_{u t}$ value is up to $60 \%$ in general reduction $\eta_{i}$. The share of non-use of the heat owing to the inopportuneness of soot combustion $\delta_{u t}{ }^{c}$ increases when value of $x^{c}$ increases; and value of $\delta_{u t}{ }^{c}$ is more than $70 \%$ in $\delta_{u t}$, when $x^{c}$ is 0,2 . A share of non-use of heat owing to radiating heat exchange $\delta_{w r}{ }^{c}$ also quickly sharply increases when $x^{c}$ increases. The increase of efficiency $\eta_{i}$ is connected with the growth of $\eta_{i}^{c}$ and the reduction of $x^{c}$.

In the Table the results of full allocation of heat losses are shown connected with the presence and burning out of soot particles in the cylinder of a diesel engine with $\xi_{b o}=0,4$ and theoretically working process with $\xi_{b o}=1$.

It is visible in the table that all coefficients of non-use of heat decrease approximately proportionally to reduction $x^{c}$ with the growth of $\mathrm{x}_{b o}$, but the coefficients of losses owing to the inopportuneness of soot combustion $\delta_{u t}{ }^{c}$ and radiating heat exchange $\delta_{w r}{ }^{c}$ decrease approximately 4 times. As a result non-use of heat is $12,7-5,84=6,86 \%$, and the reduction in the sum is $\Delta \delta_{u t}{ }^{c}+\Delta \delta_{w r}{ }^{c}=2,5 \%$, it is almost $40 \%$.

\section{Conclusions}

1. It is necessary to set the interconnected change of functions $x(\varphi), \xi_{b}(\varphi)$ and $\sigma(\varphi)$ carrying out mathematical modeling of the influence of utilization degree of cylinder air charge on soot emission, otherwise the analysis will be incomplete and inexact.

2. It is shown that the maximal concentration of soot in cycle $C_{\max }$ is reduced more than $20 \%$, and in exhaust $C g-30-40 \%$ with the increase of utilization degree of cylinder air charge (growth of coefficient $\xi_{b o}$ from 0,2 up to 1 ).
3. The quantity of the heat allocated from soot combustion $x^{c}$ increases up to $25 \%$, it depends on the quality of the organization of a working process and decreases up to $9 \%$ with the increase of coefficient $\xi_{b o}$; the efficiency of utilization of soot combustion heat changes in a range $\eta_{i}{ }^{c}=0,25-0,40$, it grows with the increase of coefficient $\xi_{b o}$ and the reduction of soot combustion heat.

4. The reasons of the indicated efficiency change are determined and the existence of potential opportunity of its increase in $6-8 \%$ is established due to the reduction of all components of non-use of heat in a cycle and mainly due to the reduction of inopportuneness of soot combustion $\delta_{u t}{ }^{c}$ and losses from radiating heat exchange $\delta_{w r}{ }^{c}$.

\section{References}

1. Matievsky, D.; Dudkin, V.; Baturin, S. Participation of soot in a running cycle of a diesel engine and indicated efficiency.Dvigatelestroenie (Двигателестроение), № 3, 1983, p. 54-56 (in Russian).

2. Razleitsev, N. Modelling and optimization of the process of combustion in diesel engines (Моделирование и оптимизация процесса сгорания в дизелях). Kharkov: High school, 1980. 169 p. (in Russia).

3. Matievsky, D. Analysis of profitability of use of heat in settlement cycle of ICE. Izvestia VUZov, Machineindustry (Известия Вузов) , No 8, 1981, p. 7174 (in Russian).

4. Baturin, S. Physical basis and mathematical modelling of processes of resulting soot emission and thermal radiation in diesel engines (Физические основы и математическое моделирование процессов результирующего сажевыделения и теплового излучения в дизелях). Diss. of dokt. degree, Leningrad, 1982. 357 p. (in Russian). 